\title{
\#NOPAINNOGAIN: NOTAS ETNOGRÁFICAS EM UMA ACADEMIA DE MUSCULAÇÃO E NAS REDES SOCIAIS INSTAGRAM E FACEBOOK
}

\author{
Ana Paula Fiori Sawamura ${ }^{1}$ (Ciências Sociais - UEL) \\ Prof ${ }^{a}$ Leila Sollberger Jeolás (Orientadora)
}

\section{RESUMO}

Com base nos estudos de Iniciação Científica (PROIC/CNPq), realizados em 2015, este trabalho tem o propósito de analisar o processo de inserção no campo de pesquisa realizado através do método etnográfico. O objeto de estudo, a "construção" e "moldagem" de corpos através da musculação e sua exposição nas redes sociais virtuais, como forma de "culto" ao corpo nas sociedades contemporâneas, determinou o lócus da pesquisa: uma academia de musculação e as redes sociais - Instagram e Facebook - que têm na fotografia seu instrumento fundamental. Os sujeitos da pesquisa são os praticantes de musculação que utilizam dessas redes sociais para expor e mostrar seus corpos "construídos" nas academias através das fotos publicadas em rede. A partir de uma etnografia exploratória nas academias de musculação e do levantamento e análise das redes sociais foi possível traçar considerações iniciais sobre o fenômeno recente da exposição da vida cotidiana e dos próprios corpos em redes sociais virtuais nas sociedades contemporâneas ocidentais.

Palavras-chave: etnografia; corpo; redes sociais.

\section{INTRODUÇÃO}

Esse trabalho se baseia em uma pesquisa etnográfica cujo método nasce em meados do século XX, precisamente nos anos de 1920, com o objetivo de questionar o olhar etnocêntrico, próprio das correntes teóricas que abordavam o Outro, $\mathrm{o}$ desconhecido - presente desde o primeiro contato entre colonizadores e colonizados, bem como nas correntes evolucionistas.

A etnografia surgiu com o intuito de observar "de dentro" outras culturas. O trabalho de campo e a observação participante se tornaram características marcantes dos antropólogos pioneiros desse novo método: Bronislaw Malinowski, com Os Argonautas do Pacífico Ocidental (1922), E. E. Evans-Pritchard, com Bruxaria, oráculos e magia entre os Azande (1937) e também com Os Nuer (1940), foram exemplos da nova face da antropologia. A etnografia continua sendo, até hoje, o principal instrumento de pesquisa para os antropólogos que levam consigo seu caderno de campo para toda a pesquisa, desde os primeiros momentos exploratórios.

Geertz (p. 91, 1997) afirma que "para entender as concepções alheias é necessário que deixemos de lado nossa concepção e busquemos ver as experiências de outros com relação à sua própria concepção do eu", ou seja, os antropólogos imergem em algo totalmente desconhecido e também no conhecido para desnaturalizar o que está naturalizado. Desta forma, ideias pré-concebidas que se tenha sobre determinado objeto

\footnotetext{
${ }^{1}$ E-mail para contato: anapfsawamura@gmail.com
} 


\section{SEMINÁRIO DE PESQUISA EM CIÊNCIAS HUMANAS - SEPECH \\ Humanidades, Estado e desafios didático-científicos \\ Londrina, 27 a 29 de julho de 2016}

de estudo serão desfeitas a partir do momento em que imergirem no grupo ou cultura a ser estudado. Velho (1978) explica que a dialética é o exercício de tornar o "exótico em familiar" e o "familiar em exótico", permitindo um bom desenvolvimento do método etnográfico. Além dessas características da etnografia, outra não menos importante é a descrição densa, segundo a qual, como nos ensina Franz Boas, tudo dever ser anotado "detalhadamente, e no detalhe do detalhe. Tudo deve ser objeto da descrição meticulosa, da retranscrição mais fiel" (LAPLANTINE, p. 77, 1991).

Este trabalho teve o intuito de expor o processo de inserção no campo por parte da pesquisadora, através da observação participante em uma academia de musculação e do levantamento e análise dos perfis e páginas selecionadas das redes sociais Instagram e Facebook. O objetivo foi buscar compreender este chamado "culto" ao corpo que "ganha cada vez mais importância na vida social. Veste-se o corpo, cuida-se do corpo, constrói-se o corpo" (BERGER, p. 1, 2008), com novas possibilidades de exposição dos corpos, além da mídia e a publicidade, e recentemente, as redes sociais virtuais.

\section{CONTEXTO DA PESQUISA}

Durante quatro meses o método etnográfico fez parte da minha rotina de futura antropóloga e pesquisadora, no contexto do lócus do meu objeto de estudo: a academia de musculação e as redes sociais virtuais.

As academias de musculação geralmente possuem a mesma estrutura arquitetônica, um grande espaço que contém os aparelhos de musculação, como descreve Sabino (p. 133, 2004): "Sua decoração é rústica e singular, misto de galpão com salão de beleza. Ferro e espelhos". Além dos aparelhos, dos espelhos, das bicicletas e esteiras, há um espaço para alongamento ou atividades que as academias oferecem e objetos que não passam despercebidos, como os aparelhos televisivos, os alto falantes com músicas pop e eletrônica e os bebedouros. Os espelhos representam parte fundamental da academia de musculação, pois é através deles que o indivíduo acompanha as execuções de seus exercícios, além de permitir atenção total ao corpo, reforçando uma atitude de controle e de vigilância corporal, um reflexo de que toda a atividade de musculação e as dietas rigorosas estão gerando algum efeito positivo. De acordo com autores como Santos e Salles (p. 92, 2009):

O espelho parece relacionado a um processo de avaliação pessoal, revelando-se com um referencial de confirmação de que as pessoas estariam amis ou menos inseridas na norma. E esse processo de confirmação é acionado a todo o momento, pois exige uma vigilância constante de que nada possa escapar do controle.

Durante minhas idas à academia de musculação, ficou claro que qualquer pessoa que pratica a musculação sabe que não é fácil realizar os exercícios. Requer concentração, força e determinação. Isso se aplica a frase "No pain no gain", que em português se traduz em "Sem dor, sem ganho" e que todos que praticam a musculação já levam como lema para um estilo de vida. É perceptível que a dor faz parte deste processo de "montagem" do corpo ideal para eles, como Le Breton (p. 43, 2008) explica: 


\section{SEMINÁRIO DE PESQUISA EM CIÊNCIAS HUMANAS - SEPECH \\ Humanidades, Estado e desafios didático-científicos \\ Londrina, 27 a 29 de julho de 2016}

O body builder, o construtor de corpo, constrói seus limites físicos [...]. Assume seu corpo como uma segunda pele, um sobrecorpo, uma carroceria protetora, com a qual se sente finalmente protegido em um universo do qual controla todos os parâmetros. Aqui encontramos a dor como enfrentamento simbólico no limite e batente provisório de uma identidade a ser construída.

Para a realização dessa pesquisa, foi necessário ir além das visitas etnográficas à academia de musculação. Como o propósito foi compreender a razão de alguns praticantes de musculação em exporem e exibirem seus corpos no ciberespaço, outro campo pertinente ao estudo foram as redes sociais Instagram e Facebook. Para a análise destas redes sociais, foi necessário fazer uma seleção de perfis de Instagram e páginas de Facebook, devido ao grande número de pessoas que possuem o mesmo objetivo nessas redes. Portanto, foram selecionados os perfis com maiores números de seguidores, e as páginas com maiores números de "curtidas", ambos que se referem à musculação.

O Facebook foi criado em 2004 por Mark Zuckerberg, Eduardo Saverin, Chris Hughes, e Dustin Moskovitz. De acordo com os dados estatísticos do site norteamericano Statista $^{2}$ (março de 2015), o Facebook possui 1.44 bilhões de usuários ativos. E para o entendimento desse estudo, vale ressaltar que as páginas de comunidades do Facebook, analisadas a priori, são criadas por alguém para que outros possam "curtir" ou "compartilhar" gostos em comum por determinados assuntos e temas, como por exemplo, a página No Pain No Gain que "posta"3 fotos, mensagens ou vídeos sobre a musculação, possuindo seguidores que dividem o mesmo interesse pelo assunto.

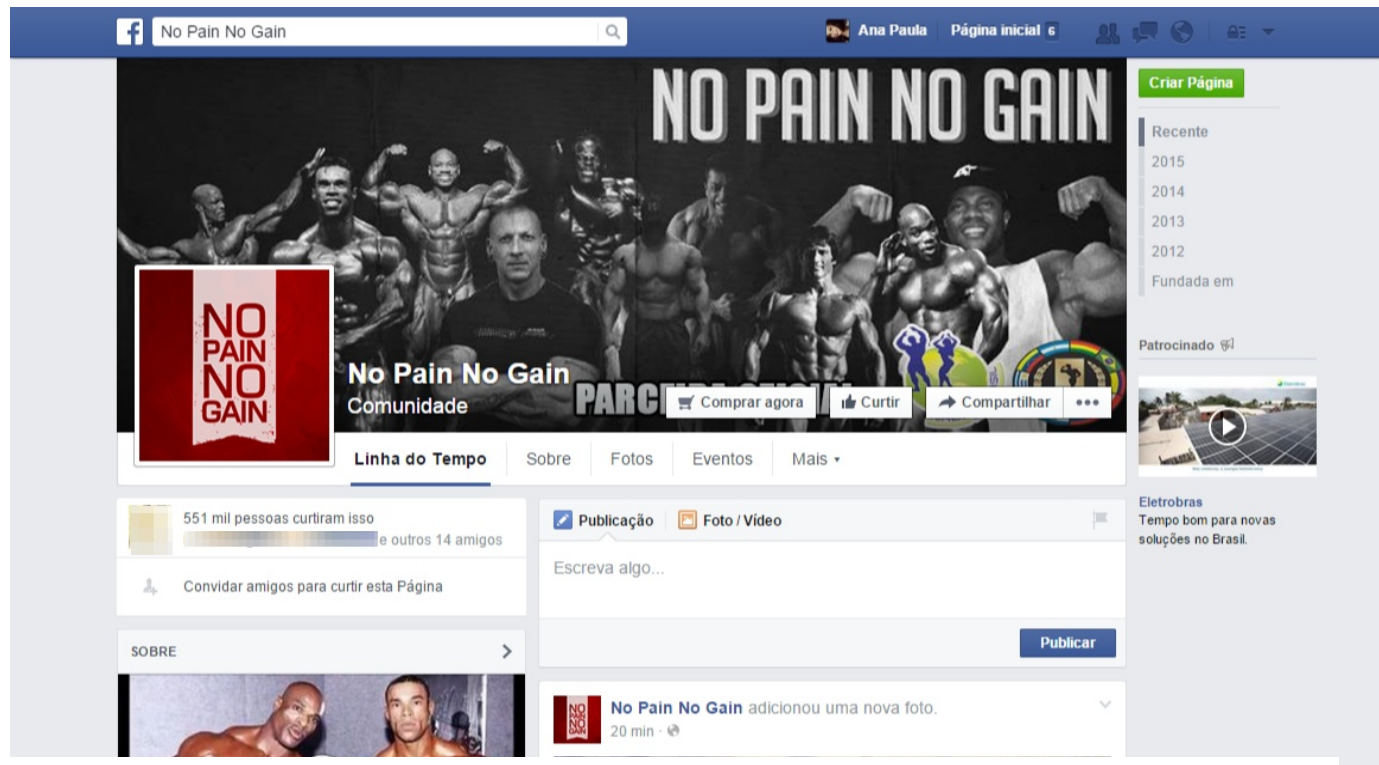

Krieger, é uma $\mathrm{r}$

Figura 1 - Fonte: Facebook (No Pain No Gain)

fotos com legendas e filtros diferenciados, e nele a forma de interações virtuais acontece através dos botões de "seguidores" e "seguindo" - followers e following. Ou seja, a

\footnotetext{
${ }^{2}$ http://www.statista.com/statistics/264810/number-of-monthly-active-facebook-users-worldwide/. Acesso em: 25 de maio de 2015.

3 "Curtir", "compartilhar", e "postar" são termos utilizados nas redes sociais da Internet.
} 


\section{SEMINÁRIO DE PESQUISA EM CIÊNCIAS HUMANAS - SEPECH \\ Humanidades, Estado e desafios didático-científicos \\ Londrina, 27 a 29 de julho de 2016}

pessoa que "segue" poderá "curtir" ou comentar a foto, assim como você poderá fazer o mesmo em relação a ela.

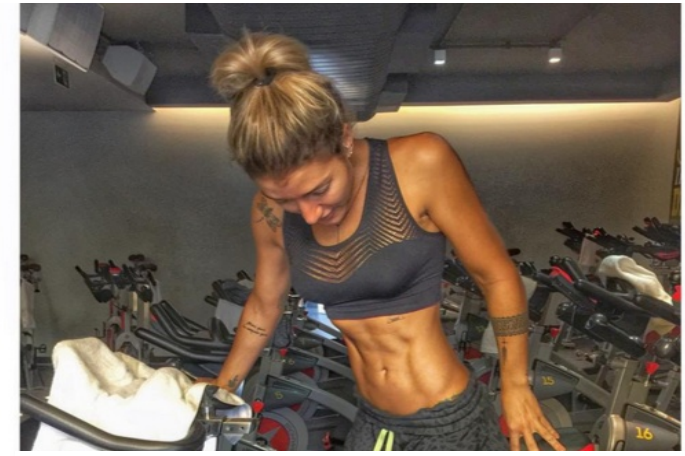

Figura 2 - Fonte: Instagram (@gabrielapugliesi)

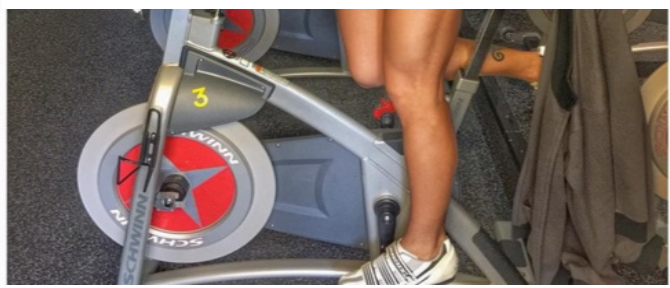

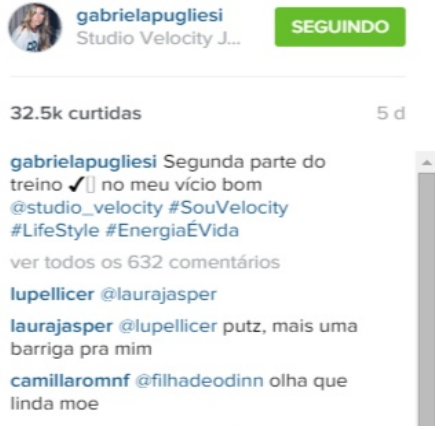

(c) estefanyalencaar ayaagooalves

dupolizelli @gustacr eu sei q VC prefere

va_benke @gabrielapugliesi Como vc mantém essa pele bronzeada? Ou su pele é naturalmente nesse tom?

Os perfis de Instagram e páginas selecionadas para a realização desse estudo foram os seguintes:

\begin{tabular}{|l|l|l|}
\hline @ therock & $@$ dbolina & @felipetitto \\
16.4 milhões de seguidores & 1.6 milhões de seguidores & 1.1 milhões de seguidores \\
\hline @jujusalimeni & $@$ bella.falconi & @laisdeleon \\
4.6 milhões de seguidores & 1.4 milhões de seguidores & 902 "k" mil seguidores \\
\hline @ fitgirlsworldwide & $@$ fefrancooficial & @femalebodymuscle_oficial \\
1.8 milhões de seguidores & 1.3 milhões de seguidores & 752 "k" mil seguidores \\
\hline @schwarzenegger & @videosdetreino & @lionshulz \\
1.8 milhões de seguidores & 1.3 milhões de seguidores & 506 "k" mil seguidores \\
\hline @graoficial & $@$ gabrielapugliesi & @dicas_musculacao \\
1.7 milhões de seguidores & 1.2 milhões de seguidores & 506 " $\mathrm{k}$ " mil seguidores \\
\hline
\end{tabular}

Tabela 1

Academia - Minha segunda casa (605.158 curtidas)

https://www.facebook.com/loveacademia?fref $=$ ts

No Pain No Gain (552.072 curtidas)

https://www.facebook.com/PaginaNoPainNoGain?fref=ts

Dicas de Musculação (485.578 curtidas)

https://www.facebook.com/dicademusculacao?fref=ts

Eu curto musculação/academia (474.592 curtidas)

https://www.facebook.com/CurtoMusculacao?fref $=$ ts

Sem dor, sem glória (384.423 curtidas) 


\section{SEMINÁRIO DE PESQUISA EM CIÊNCIAS HUMANAS - SEPECH \\ Humanidades, Estado e desafios didático-científicos \\ Londrina, 27 a 29 de julho de 2016}

https://www.facebook.com/EuNaoMalhoEuTreino?fref=ts

\section{Tabela 2}

Os perfis de Instagram selecionados para esse estudo foram os que possuem maior número de seguidores e que se referem ao assunto da musculação. Os usuários destes perfis são os que hoje são chamados de blogueiros ${ }^{4}$. Essas pessoas não são necessariamente atrizes, atores, cantores, mas devido ao número alto de "seguidores" acabam virando garoto ou garota propaganda de marcas de roupas de ginástica, de suplementos alimentares, de nutricionistas, personal trainers, e de outros produtos ligados ao ramo da musculação, alimentação e beleza.

O conteúdo divulgado nessas redes sociais é o mesmo: dicas de musculação, de como fazer o "treino" de maneira a obter melhor desempenho e maior resultado ou de exercícios que podem ser feitos em casa; dicas de alimentação, de quais alimentos podem ajudar no ganho de massa muscular e na perda de peso (da massa gorda), de que maneira a alimentação deve ser feita; no caso dos blogueiros - para fazer propagandas e ganhar patrocínios de empresas - dicas dos melhores produtos no mercado, normalmente voltados à alimentação, que podem ajudar nesta busca pelo corpo ideal.

\section{CORPO, IDENTIDADE E SOCIABILIDADE: NAS ACADEMIAS E REDES SOCIAIS}

Os blogueiros que antes foram meros praticantes de musculação e, atualmente, alcançaram a fama do mundo da musculação, através das redes sociais, agora são uma das peças fundamentais do mercado do músculo (COURTINE, p. 84, 1995), este que nada mais é do que o próprio "consumo de bens e serviços destinados à manutenção do corpo". É visível a força e o poder que a mídia adquiriu e ainda adquiri na sociedade ocidental contemporânea, como explica Goldenberg e Ramos (2002):

\section{A mídia adquiriu um imenso poder de influência, expandiu o consumo de produtos de beleza, generalizou a paixão pela moda e tornou a aparência física responsabilidade de cada indivíduo, que não deve mais aceitar seu corpo tal como ele é, como "obra da natureza", mas sim procurar corrigir suas "imperfeições". [...] Nesse processo de responsabilização do indivíduo pelo seu corpo, a mídia e, especialmente a publicidade, possuem um papel fundamental. O corpo virou o 'mais belo objeto de consumo' (Baudrillard, s/d) e a publicidade [...] hoje em dia serve, principalmente, para produzir o consumo como estilo de vida, procriando um produto próprio: o consumidor, perpetuamente intranquilo e insatisfeito com sua aparência (Lasch, 1983).}

O significado que o corpo adquiriu nas sociedades contemporâneas, segundo Le Breton (p. 31, 2008) é o de ser manipulável e em construção permanente, como no caso dos praticantes de musculação. Ele constitui alter ego[...]disponível a todas as modificações, prova radical e modulável da existência pessoal e exibição de uma identidade escolhida provisória e duravelmente" (LE BRETON, p. 28, 2008). Além

\footnotetext{
${ }^{4}$ Blogueiros são pessoas que possuem um blog, que por sua vez são páginas da Internet onde são publicados os "posts" que são conteúdos que o criador do blog escolhe. Nesta pesquisa, os blogueiros são os possuidores de perfis de Instagram.
} 


\section{SEMINÁRIO DE PESQUISA EM CIÊNCIAS HUMANAS - SEPECH \\ Humanidades, Estado e desafios didático-científicos \\ Londrina, 27 a 29 de julho de 2016}

disso, o consumo se tornou parte integrante da busca pelo corpo desejado. Courtine (p. 86, 1995) afirma que "nas sociedades ocidentais, a cultura contemporânea do corpo é inteiramente dominada pelo ciclo da absorção e da eliminação, tanto orgânico, quanto econômico".

O corpo exaltado e buscado a cada dia pelos que praticam a musculação e que seguem uma dieta rígida e pensada para a construção do corpo, é o corpo trabalhado, talhado a partir de seus músculos que antes não apareciam visivelmente, mas com os "treinos" cotidianos, com as dietas e os suplementos alimentares, começam a "ganhar vida". O autor Le Breton (p. 42, 2008) explica este trabalho do body builder sobre a construção de seu corpo: "Peça por peça, o body builder constrói seu corpo à maneira de um anatomista meticuloso preso apenas à aparência subcutânea".

O desejo de seguir tais padrões de beleza move a busca para a produção deste corpo ainda em estágio inicial ou um "rascunho" do que poderá ser. E não apenas os que estão começando, mas os que já praticam a musculação há muito tempo, também buscam incentivo para continuar e perseverar nesta busca. Aliás, durante minha pesquisa de campo pude observar que não é fácil se submeter a uma hora do seu dia para levantar pesos que fazem doer os músculos, como também (e principalmente) após os "treinos". Isto porque eu nem havia me sujeitado a começar dietas rigorosas que estes praticantes precisam fazer para conseguir o resultado esperado.

O papel das redes sociais como incentivo é recente e algo a ser estudado ainda. Segundo Recuero (2009), as redes sociais englobam dois elementos: os atores e suas conexões. O primeiro elemento diz respeito ao sujeito dessa rede social, no caso da presente pesquisa, os usuários dos perfis de Instagram e os donos das páginas de Facebook. E as conexões "são constituídas dos laços sociais, que, por sua vez, são formados através da interação social entre os atores" (RECUERO, 2009, p. 30), ou seja, é a partir da interação que se dá os laços sociais entre os atores das redes. Na pesquisa em questão, os laços sociais que se dão nestas redes sociais analisadas são fracos, devido ao número alto de seguidores que cada perfil de Instagram possui e também devido ao número alto de usuários que "curtem" as páginas analisadas de Facebook. Torna-se difícil e trabalhoso responder à, por exemplo, 1200 comentários que uma imagem recebeu em determinada rede social (perfil ou página). Essa fragilidade dos laços sociais diz respeito à própria forma desse tipo de comunicação e de sociabilidade (RECUERO, 2009).

Neste sentido, pode se afirmar que a rede social se torna um incentivo, na medida em que estes atores sociais (RECUERO, 2009) criam conexões entre si, mas não necessariamente laços sociais. Pois o simples ato de começar a seguir determinado perfil de Instagram, curtir uma página de Facebook, ou dar uma "curtida" na imagem ou foto "postada", já é considerado uma conexão entre o ator do perfil $X$ com o ator do perfil $Y$, mesmo que os atores não queiram criar laços sociais por meio de respostas dos comentários deixados em sua foto ou imagem "postada". Há, portanto, uma relação de interdependência entre ambos os atores.

Esta relação de interconexão aparece da seguinte maneira nas redes sociais utilizadas pelos praticantes de musculação: os blogueiros com maior número de seguidores, que se tornaram um tipo de celebridade, precisam de seus seguidores e de suas "curtidas" para ter maior visibilidade e status - sendo que este dispositivo de "curtir" ou "dar likes" é "visto como uma forma de apoio e visibilidade, no sentido de mostrar para a rede que se está ali" (RECUERO, p. 119, 2014) - e os praticantes de musculação que estão em busca de dicas e motivações para se conseguir o corpo tão 


\section{SEMINÁRIO DE PESQUISA EM CIÊNCIAS HUMANAS - SEPECH \\ Humanidades, Estado e desafios didático-científicos \\ Londrina, 27 a 29 de julho de 2016}

desejado, consequentemente, são levados a "seguir" esses blogueiros que já estão alcançando este objetivo e conseguiram propagar tal conquista através de seu perfil ou página na rede social. Claro que os praticantes "comuns" que não possuem um número alto de seguidores na rede social, além de buscarem o corpo "perfeito", também almejam a visibilidade que os blogueiros possuem, pois querem mostrar a todos que conseguiram através de "treinos" diários e dietas a ter o tão desejado corpo.

Essa visibilidade que os praticantes de musculação querem e buscam nas redes sociais, segundo Paula Sibilia (2009) é o próprio reconhecimento na luz das telas de notebooks, tablets, e celulares, é "ser alguém", como explica a própria autora:

Essa visibilidade promete nos conceder a tão prezada celebridade. E, por si mesmas, essas condições parecem capazes de legitimar a existência daqueles que conseguem conquista-las: ser visto e ser famoso equivale, cada vez mais, a ser alguém [...] em nossa sociedade do espetáculo só é aquilo que se vê, e por isso é necessário aparecer para que os olhares alheios confirmem a própria existência. Trata-se daquilo que se espera de nós: é o nosso modo de ser contemporâneo.

\section{CONSIDERAÇÕES FINAIS}

Neste sentido, além de incentivo, visibilidade e status, o que parece mais relevante é o fato das redes sociais servirem também para fixar e de certo modo imortalizar o corpo que o praticante de musculação construiu e definiu durante seus "treinos" e dietas rígidas. Elas fizeram isso a partir da fotografia - ferramenta crucial de toda rede social - e se tornou o documento real de que seu corpo agora faz parte do padrão de beleza divulgado pela mídia (SIBILIA; DIOGO, p. 129, 2011). A partir desta construção do corpo e da exposição dele, compreende-se que o ator social quer visibilidade, status e popularidade tanto no mundo virtual, como no mundo "real".

Paula Sibilia (2009), autora que trata da exposição dos indivíduos na Internet, aponta que a nossa ideia de intimidade está mudando, "hoje o espaço íntimo se converte numa espécie de cenário onde cada um deve montar o espetáculo de sua própria personalidade". Por isso que, por terem o trabalho de construir seus corpos através dos "treinos" e das dietas, os praticantes de musculação querem mostrar aos outros que eles conseguiram ou estão conseguindo obter o resultado esperado do corpo "perfeito" e esta exposição em larga escala só é possível graças às redes sociais.

De acordo com Sibilia (2011), o culto ao corpo nas redes sociais pode ser apresentado no simples ato de "curtir" uma foto de algum corpo tido como "perfeito". Ou também, pela foto de seu próprio corpo "postada" em seu Instagram, onde muitas pessoas podem ter acesso e ver o que está para ser mostrado. Segundo a autora, essa ânsia de mostrar sua vida privada, ou no caso desta pesquisa, o corpo "em produção", é apenas reflexo da necessidade de ser visto.

\section{REFERÊNCIAS BIBLIOGRÁFICAS}

BERGER, Mirela. As chaves do templo. Ponto URBE, São Paulo, v. 2, n. 2, p. 1-15, fev. 2008. 


\section{SEMINÁRIO DE PESQUISA EM CIÊNCIAS HUMANAS - SEPECH \\ Humanidades, Estado e desafios didático-científicos \\ Londrina, 27 a 29 de julho de 2016}

COURTINE, Jean-Jacques. Os stakhanovistas do narcisismo: body-building e puritanismo ostentatório na cultura americana do corpo. In: SANT'ANNA, Denise Bernuzzi (Org.). Políticas do corpo. 1ªed. São Paulo: Estação Liberdade, 1995. p. 81114.

GEERTZ, Clifford. "Do ponto de vista dos nativos": a natureza do entendimento antropológico. In: _ O Saber local: novos ensaios em antropologia interpretativa. Petrópolis, Rio de Janeiro: Vozes, 1997. p.85-107.

GOLDENBERG, Mirian; RAMOS, Marcelo Silva. O corpo carioca (des)coberto. In: CASTILHO, Kathia; GALVÃO, Diana. A moda do corpo o corpo da moda. $1^{\mathrm{a}}$ ed. São Paulo: Editora Esfera, 2002. p. 111-125.

LAPLANTINE, François. Os pais fundadores da etnografia. In: Aprendendo Antropologia. $5^{\text {a }}$ ed. São Paulo: Brasiliense, 1991. p.75-86.

LE BRETON, David. Adeus ao corpo: Antropologia e Sociedade. $3^{\text {a }}$ ed. Campinas, São Paulo: Editora Papirus, 2008. 240p.

RECUERO, Raquel. Curtir, compartilhar, comentar: trabalho de face, conversação e redes sociais no Facebook. Verso e Reverso, Pelotas, Rio Grande do Sul, v. 28, n. 68, p. 114-124, mai./ago. 2014.

RECUERO, Raquel. Redes sociais na Internet. Porto Alegre, Rio Grande do Sul: Editora Sulina, 2009. 191p.

SABINO, César. O peso da forma: cotidiano e uso de drogas entre fisiculturistas. 2004. 342f. Tese (Doutorado) - Universidade Federal do Rio de Janeiro, Rio de Janeiro.

SANTOS, Sandra Ferreira dos; SALLES, Adilson Dias. Antropologia de uma academia de musculação: um olhar sobre o corpo e um espaço de representação social. Revista Bras. Educ. Fís. Esporte, São Paulo, v.23, n.2, p.87-102, abr./jun. 2009.

SIBILIA, Paula. Mírenme, soy yo!. La mujer de mi vida, Buenos Aires, Argentina, v. 9, n. 64, 2011. Disponível em: $<$ http://www.lamujerdemivida.com.ar/index.php?option=com_content\&view=article\&i $\mathrm{d}=358>$. Acesso em: 18 maio 2015.

SIBILIA, Paula. O espetáculo do eu. Mente e Cérebro, fev. 2009. Disponível em: $<$ http://www2.uol.com.br/vivermente/reportagens/o espetaculo do eu.html>. Acesso em: 18 maio 2015.

SIBILIA, Paula; DIOGO, Lígia. Vitrines da intimidade na internet: imagens para guardar ou para mostrar?. Estud. Sociol., Araraquara, v. 16, n. 30, p. 127-139. 2011.

VELHO, Gilberto. Observando o Familiar. In: NUNES, Edson (org.). A Aventura Sociológica. Rio de Janeiro: Zahar, 1978. 